\title{
OCUPAÇÃO ESPACIAL MIGRAÇÃO E MOBILIDADE URBANA: A CONSTRUÇÃO ECONÔMICA DE IMPERATRIZ-MA
}

Space Occupation Migration And Urban Mobility: The Economic Construction Of Imperatriz-MA

Migración De Ocupación Espacial Y Movilidad Urbana: La Construcción Económica

De Imperatriz-MA

\section{Jorcelyo Alencar Lima ${ }^{1}$, Elisangela de Andrade Borges Alencar ${ }^{2}$}

${ }^{1}$ Programa de Pós-graduação do Mestrado Profissional em Gestão de Políticas Públicas na Universidade Federal do Tocantins - UFT, Palmas, Brasil.

${ }^{2}$ Especialização em Estatística Aplicada as Ciências da Universidade Estadual do Maranhão - UEMA, Imperatriz, Brasil.

*Correspondência: Rua José Bonifácio n 597, Mercadinho, Imperatriz - MA CEP:65.901-380. e-mail j.alencar2008@hotmail.com

Artigo recebido em 22/03/2020 aprovado em 30/10/2020 publicado em 30/12/2020.

\section{RESUMO}

Partindo de uma abordagem sobre ocupação e aglomeração espacial em escala nacional, este artigo orienta-se pelas migrações internas objetivando discutir questões de mobilidade urbana, utilizando como exemplo a construção econômica do município de Imperatriz originada por fluxos migratórios a partir da segunda metade do século XX. No estudo dessa construção o método materialismo-histórico auxilia na busca para se constituir os elementos necessários à compreensão do fenômeno migratório, enquanto processo histórico-social, constituinte da própria dinâmica da construção econômica desse município.

Palavras-chave: Migração. aglomeração. mobilidade.

\section{ABSTRACT}

Starting from an approach to occupation and spatial clustering on a national scale, this article is guided by internal migration aiming to discuss issues of urban mobility, using as an example the economic construction of the city of Imperatriz, caused by migration from the second half of XX century. In the study of this construction, materialism-historical method helps in the quest to provide the elements necessary for understanding the phenomenon of migration, while social-historical process, constituent of the dynamics of economic construction this city.

Keywords: Migration. Clustering. Mobility.

\section{RESUMEN}

Partiendo de un enfoque de ocupación y aglomeración espacial a escala nacional, este artículo se guía por las migraciones internas con el objetivo de discutir temas de movilidad urbana, tomando como ejemplo la construcción económica del municipio de Imperatriz originada por los flujos migratorios de la segunda mitad del siglo XX. En el estudio de esta construcción, el método materialismo-histórico ayuda en la búsqueda de constituir los elementos necesarios para comprender el fenómeno migratorio, como un proceso histórico-social, constituyendo la dinámica de la construcción económica de este municipio.

Descriptores: Migración. Aglomeración. Movilidad. 


\section{INTRODUÇÃO}

As aglomerações urbanas originadas por processos migratórios podem criar certos entraves na mobilidade urbana das cidades. As dificuldades iniciais de habitação para o migrante somam-se aos obstáculos de locomoção das pessoas, principalmente de casa para o trabalho em virtude da complexidade para manter redes de transportes coletivos, disponíveis em todo o perímetro urbano, inclusive contemplando áreas de expansão que surgem na iminência das aglomerações urbanas. As questões de mobilidade urbana, quando não planejadas na perspectiva dos prováveis fluxos migratórios, podem acarretar consequências de meios de transportes insuficientes para determinados municípios, exigindo maiores investimentos sobre a infraestrutura urbana, projetada no passado.

Discutir a mobilidade urbana neste trabalho envolve um nível de complexidade caracterizada pelas transformações do sistema produtivo vigente na sociedade brasileira. Deste modo observam-se as pessoas e seus respectivos meios de locomoção nas diversas atividades, suas possibilidades pecuniárias para utilizar meios de transporte e estes com as adaptações coerentes com os distintos usuários; as rotinas dos deslocamentos e a relação de dependência, que implica nas viagens diárias (idas e vindas) para o exercício do trabalho, as quais se modificam em função das transformações capitalistas. Os aspectos físicos e geográficos estão inseridos também nesta problemática em função das diversas localizações e os níveis de acesso, considerando os fatores tempo e dinheiro, vinculados às distâncias, que ligam trabalho, escola e os centros de abastecimento.

As distintas lidas do cotidiano apresentadas acima, que envolve as pessoas nas práticas habituais de uma sociedade, neste século XXI justifica conceituar mobilidade, como a facilidade de moverse ou ser movido (FERREIRA, 2013). Mobilidade pessoal explicada a partir de Morris (1979, p. 91109), é considerada como a capacidade que uma pessoa de se deslocar de um lugar para outro se utilizando dos diversos meios de transporte, inclusive com os próprios meios quando as distâncias, os acessos e as condições físicas permitem.

A valorização sobre temas que associam ocupação espacial, migração e mobilidade urbana atingiu níveis elevados a partir de 1970, quando o Censo Demográfico brasileiro passou a mostrar dados que estabeleciam o início de uma mobilização do meio rural para o urbano, com população rural em $1960=38.987 .526$ e urbana $32.004 .817(54,9 \%$ e $45,1 \%$ ); população rural em $1970=41.603 .839 \mathrm{e}$ urbana 52.904 .744 (44,0\% e 56,0\%), demonstrando assim uma mudança na configuração da estrutura de produção do país e consequentemente uma reestruturação na distribuição espacial da população do meio rural e urbano, sendo este, naquela ocasião, década de 1970 o espaço que exercia maior força de atração, porque o grande crescimento econômico era demonstrado pela geração de emprego e renda no setor urbano. Essa mudança prosseguiu como mostra o quadro a seguir, se aproximando para uma população totalmente urbana.

Quadro 1. Distribuição da população brasileira / urbana e rural - 1960 a 2010.

\begin{tabular}{|c|c|c|c|c|c|c|}
\hline População & $\mathbf{1 9 6 0}$ & $\mathbf{1 9 7 0}$ & $\mathbf{1 9 8 0}$ & $\mathbf{1 9 9 1}$ & $\mathbf{2 0 0 0}$ & $\mathbf{2 0 1 0}$ \\
\hline Urbana & 32.004 .817 & 52.904 .744 & 82.013 .375 & 110.875 .826 & 137.755 .550 & 160.925 .792 \\
\hline Rural & 38.987 .526 & 41.603 .839 & 39.137 .198 & 36.041 .633 & 31.835 .143 & 29.830 .007 \\
\hline
\end{tabular}

Fonte: IBGE, Censo Demográfico 1960, 1970, 1980, 1991, 2000 e 2010. Elaboração do autor. 
Observa-se no Quadro 1 acima uma progressão no sentido da urbanização, que se pode relacionar como fatores de influência, o emprego de novas tecnologias de alta produtividade no campo; redução da expectativa de geração de emprego da mão de obra no meio rural; a abertura de novos postos de trabalho no meio urbano e a grande concentração dos serviços públicos essenciais no setor urbano.

$\mathrm{Na}$ base desses novos fatores que promovem a saída do meio rural está o problema da reforma agrária brasileira, que é caracterizado pela lentidão dos processos e as divergências nas execuções, que apesar da criação de órgão específico para cuidar do referido problema, como é o caso do Instituto Nacional de Colonização e Reforma Agrária (INCRA), que atua há quase meio século (46 anos), mas não é possível festejar ganhos sociais proporcionais a esses anos de luta pela reforma agrária, considerando que ainda permanece a grande concentração fundiária conforme índice de Gini $^{1}$ de 2003 (GIRARDI, 2010, p. 41-65).

No presente artigo não há qualquer pretensão de aprofundamento sobre essa questão agrária brasileira, mas de fazer essa breve referência, buscando uma reflexão para essa realidade, que une a tradição histórica da posse da terra, os latifúndios (improdutivos) e a recente estratégia de concentração de grandes áreas para a produção de commodities agrícolas, com o emprego de tecnologias altamente produtivas. Essa concepção induz a acreditar em um inexorável processo de urbanização, como indicam os números do quadro acima.

10 índice de Gini é medido em uma escala de 0,000 a 1,000 , em que o zero representa distribuição de terras absolutamente igual e o um, uma distribuição de terras totalmente desigual. $O$ índice de 0,854 mostra que há uma estabilidade na concentração fundiária no país pelo menos nos últimos 20 anos, já que o índice de 1985 era de 0,857 e o de 1995/96, de 0,856 (IBGE, 2009).
Diante dessas considerações iniciais, este artigo propõe discutir as questões de mobilidade urbana, utilizando como exemplo a ocupação espacial do município de Imperatriz, originada por fluxos migratórios, a partir da segunda metade do século XX. Visando atingir essa proposição, este trabalho estrutura-se em cinco seções, incluindo a presente introdução mais uma segunda seção com descrição e análise de mobilidade urbana; a terceira versando sobre migração e mobilidade urbana; a quarta abordando aglomeração urbana condicionada pela migração e por fim as considerações finais.

\section{MOBILIDADE URBANA}

Com o propósito de esclarecer sobre as necessidades de deslocamentos das pessoas no espaço urbano, é importante ressaltar o estudo desenvolvido pelo Instituto de Pesquisas Econômicas Aplicadas (IPEA), através da Nota Técnica da Diretoria de Estudos e Políticas Regionais, Urbanas e Ambientais (NT Dirur $\mathrm{n}^{\circ}$ 02/2013, p. 03-23), sobre transporte público no Brasil. Esse estudo analisa um aspecto da mobilidade urbana referente ao transporte público urbano, em todas as capitais dos estados. Foram pesquisadas mais de 44 cidades brasileiras, com população superior a 500 mil habitantes e os resultados apontam para a necessidade de se constituir mecanismos alternativos de financiamento do sistema de transporte público e de modernizar a infraestrutura quanto à prestação de serviço, desonerando, sobretudo, as classes de renda mais baixas, de pesados encargos para custear os seus baixos índices de mobilidade (BALBIM, 2013, p. 7 13).

Os mais frequentes usuários desse meio de deslocamento estão nas classes de baixa renda, que comprometem $15 \%$ (quinze por cento) da renda com transporte. (NT Dirur $n^{\circ}$ 02/2013, p. 03-23). A Lei federal número 12.587, de 03 de janeiro 2012 criou 
normas no âmbito da habitação, saneamento básico, integração entre os modos e serviços de transporte público coletivo, que de modo geral, garantem os deslocamentos facilitados de pessoas a partir de uma harmonização espacial (Lei 12.587/ 2012, Art. 0128).

O serviço de transporte público convive com a ocupação espacial do final do século XX e início do século atual quando se inseri as ações das incorporadoras imobiliárias ${ }^{2}$, responsáveis pelos projetos de ampliação do espaço urbano, que priorizam a urgência das construções habitacionais, em detrimento de um acurado planejamento ambiental, que deveria contemplar principalmente a necessidade de deslocamentos cotidianos para o trabalho e escola. Muitos projetos foram elaborados, mas não tiveram o devido amadurecimento. A dependência econômica global pode impedir que medidas de planejamento sejam executadas estrategicamente, dando origem a decisões de forma extraordinária, mas que produzem consequências sociais onerosas.

A emergência do crescimento econômico, sobretudo como gerador de renda é capaz de ocultar a importância do desenvolvimento quanto ao aspecto da melhoria da qualidade de vida da população nos seus elementos básicos de acessibilidade, educação, saúde etc. Nesse crescimento, a necessidade de ampliar a produção de automóveis parece antever outros investimentos e/ou subsídios na construção de estruturas de mobilidade urbana. Assim essa mobilidade é comumente discutida tendo como base o volume de veículos automotores já existentes em determinado espaço urbano, considerando que esse parâmetro, caracterizado por essa variável, vem

\footnotetext{
2 Empresas que organiza um conjunto de atividades exercidas com a finalidade de construir ou promover a construção de edificações ou conjunto de edificações, bem como a sua comercialização, total ou parcial, compostas de unidades autônomas que, em seu conjunto, formam um condomínio.
}

apresentando rápidas e evidentes modificações, superando medidas em favor da mobilidade urbana.

Os números registrados pelo Departamento Nacional de Trânsito mostram que, nos últimos anos o aumento de veículos automotores no Brasil foi muito elevado. Em 2001 o número de automóveis era aproximadamente 24,5 milhões, passando para 50,2 milhões em 2012 registrando assim, um crescimento de 104,5\%. Esse acréscimo no número de veículos nas metrópoles ou em cidades populosas e de grande crescimento econômico eleva a probabilidade de déficit de mobilidade urbana (OBSERVATÓRIO DAS METRÓPOLIS/INCT/DENATRAN, 2012/ 2013, p. 04-38).

O aumento do número de veículos no Brasil conforme dados do parágrafo anterior pode ser justificado em função de vários fatores, como problemas do transporte coletivo evidenciados pela falta de transporte, de linhas e horários necessários. Esses aspectos foram assinalados em pesquisas do Instituto de Pesquisas Econômicas Aplicadas (IPEA), em que $39 \%$ dos brasileiros consideram o transporte coletivo como péssimo e ainda $32,6 \%$ apontam a falta de segurança como um grande problema para o usuário desse tipo de transporte (IPEA, 2011, p. 634).

Em função dos problemas do transporte coletivo é importante ressaltar alguns fatores, que estão relacionados com a propensão de consumir um automóvel, Cristo (2013, p. 114-128) afirma que, a literatura da área de psicologia aponta pelo menos três categorias (instrumental, afetivo e simbólico) de tendências para o uso do transporte individual, que geram motivos como chegar rápido aos lugares, estar acessível na garagem, as emoções de se fazer aparecer ao usar um veículo, e porque o carro é uma expressão do seu próprio jeito (STEG, 2005, p. 2-12; GATERSLEBEN, 2007, p. 676-679; JAKOBSSON, 2007, p.205-217). 
No Brasil esses fatores ligados à predisposição de consumir um transporte individual tiveram grandes incentivos a partir da primeira década deste século. Com a crise de 2008, ou seja, a conhecida crise imobiliária dos Estados Unidos, que se irradiou pelo mundo, criando uma aversão ao risco e a um movimento generalizado de fuga dos investidores globais. A repercussão no Brasil foi caracterizada pela desaceleração da atividade econômica em consequência da redução do crédito (PRATES; FARHI, 2009; FREITAS, 2009, p.62-91).

Motivado por essa crise, o governo brasileiro adotou medidas econômicas, visando estimular o consumo em diversos setores destacando-se material de construção, agricultura, móveis e eletrodomésticos e principalmente no setor automotivo onde o carro de motor 1.0 (um ponto zero) passou a ser vendido com isenção de IPI, assim como, os financiamentos de motocicletas, motonetas e ciclomotores foram isentos de Impostos sobre Operações Financeiras (IOF)
(PRATES; CUNHA; LÉLIS, 2011, p. 123-139; SINGER, 2009, p. 43-49; TCU, 2009, p. 1-2).

Estabelecer uma relação entre essas ações do governo e a mobilidade urbana é admitir que a geração de empregos originada a partir das medidas de incentivo à produção estimulou a aquisição de bens, como casas construídas dentro das áreas de expansão urbana dos municípios que, concomitantemente ampliou a propensão de consumo de veículos em função da necessidade de deslocamento para novos espaços habitacionais, ou seja, fora da zonas dos segmentos produtivos e que de um modo geral não estavam dentro das trajetórias cobertas por linhas regulares e tradicionais de transportes coletivos. Houve também geração de empregos e principalmente na indústria da construção civil. Uma amostra dos resultados obtidos através da expansão desse crescimento pode ser observada no Quadro 2 a seguir.

Quadro 2. Posse de automóvel e motocicleta pelas famílias por faixa de renda familiar per capita - Brasil 2012.

\begin{tabular}{|c|c|c|c|c|c|c|}
\hline \multicolumn{2}{|c|}{ Faixa de renda em salários mínimos } & Tem carro & Tem moto & Tem carro e moto & Não tem carro e moto & Total \\
\hline Até $1 / 4 \mathrm{SM}$ & $\begin{array}{c}\text { Domicílios } \\
\% \text { na faixa de renda }\end{array}$ & $\begin{array}{c}249.800 \\
6,5 \%\end{array}$ & $\begin{array}{c}755.902 \\
19,7 \%\end{array}$ & $\begin{array}{l}76.777 \\
2,0 \%\end{array}$ & $\begin{array}{c}2.754 .282 \\
71,8 \%\end{array}$ & $\begin{array}{r}3.836 .761 \\
100,0 \%\end{array}$ \\
\hline $\begin{array}{l}\text { De } 1 / 4 \text { até } 1 / 2 \\
\text { SM }\end{array}$ & $\begin{array}{c}\text { Domicílios } \\
\% \text { na faixa de renda }\end{array}$ & $\begin{array}{c}1.311 .216 \\
14,3 \%\end{array}$ & $\begin{array}{c}1.562 .282 \\
17,1 \%\end{array}$ & $\begin{array}{c}328.221 \\
3,6 \%\end{array}$ & $\begin{array}{c}5.950 .388 \\
65,0 \%\end{array}$ & $\begin{array}{r}9.152 .107 \\
100,0 \%\end{array}$ \\
\hline De $1 / 4$ até 1 & $\begin{array}{c}\text { Domicílios } \\
\% \text { na faixa de renda }\end{array}$ & $\begin{array}{c}4.096 .212 \\
23,3 \%\end{array}$ & $\begin{array}{c}2.462 .684 \\
14,0 \%\end{array}$ & $\begin{array}{c}1.113 .427 \\
6,3 \%\end{array}$ & $\begin{array}{l}9.928 .734 \\
56,4 \%\end{array}$ & $\begin{array}{c}17.601 .057 \\
100,0 \%\end{array}$ \\
\hline De 1 até 2 & $\begin{array}{c}\text { Domicílios } \\
\% \text { na faixa de renda }\end{array}$ & $\begin{array}{c}6.497 .859 \\
39,6 \%\end{array}$ & $\begin{array}{c}1.745 .136 \\
10,6 \%\end{array}$ & $\begin{array}{c}1.869 .525 \\
11,4 \%\end{array}$ & $\begin{array}{l}6.287 .271 \\
38,3 \%\end{array}$ & $\begin{array}{c}16.399 .791 \\
100,0 \%\end{array}$ \\
\hline De 2 até 3 & $\begin{array}{c}\text { Domicílios } \\
\% \text { na faixa de renda }\end{array}$ & $\begin{array}{c}3.063 .676 \\
55,3 \%\end{array}$ & $\begin{array}{c}313.857 \\
5,7 \%\end{array}$ & $\begin{array}{c}826.098 \\
14,9 \%\end{array}$ & $\begin{array}{c}1.339 .564 \\
24,2 \%\end{array}$ & $\begin{array}{l}5.543 .195 \\
100,0 \%\end{array}$ \\
\hline De 3 até 5 & $\begin{array}{c}\text { Domicílios } \\
\% \text { na faixa de renda }\end{array}$ & $\begin{array}{c}2.469 .314 \\
64,8 \%\end{array}$ & $\begin{array}{c}139.558 \\
3,7 \%\end{array}$ & $\begin{array}{c}506.809 \\
13,3 \%\end{array}$ & $\begin{array}{c}694.668 \\
18,2 \%\end{array}$ & $\begin{array}{c}3.810 .349 \\
100,0 \%\end{array}$ \\
\hline Mais de 5 & $\begin{array}{c}\text { Domicílios } \\
\% \text { na faixa de renda }\end{array}$ & $\begin{array}{c}2.325 .757 \\
76,2 \%\end{array}$ & $\begin{array}{c}37.662 \\
1,2 \%\end{array}$ & $\begin{array}{c}329.466 \\
10,8 \%\end{array}$ & $\begin{array}{c}358.807 \\
11,8 \%\end{array}$ & $\begin{array}{c}3.051 .692 \\
100,0 \%\end{array}$ \\
\hline
\end{tabular}

Fonte: Microdados PNAD, 2012 IBGE/IPEA. Elaborado pelo autor.

As medidas de incentivo sobre o IOF e IPI foram incrementadas pelas facilidades creditícias, com o reforço da ampliação de parcelamento de prestações, permitindo aos consumidores acesso a esses bens que antes não tinham. Observando a menor faixa de renda per capita no Quadro 1, a motocicleta é o veículo predominante nos 755.902 domicílios, representando um acréscimo de 10\% 
nesse período de 2008 a 2012 (PNAD, 2012). As demais variáveis existentes nesse quadro respondem de forma geral, pelo incremento de aproximadamente $9 \%$, significando que $45 \%$ dos domicílios brasileiros em 2008 possuíam carro ou moto passando para 54\% em 2012. Registrou-se desde o ano de 2001 até 2012, um crescimento de 508,75\% no número de motos na região Nordeste, superando nesse período o Sudeste com crescimento de $283,9 \%$, Sul com $259,8 \%$, Norte e Centro-Oeste $187,5 \%$ e $139,9 \%$, respectivamente. A necessidade de buscar alternativas de crescimento promoveu de forma rápida uma nova dinâmica, especialmente nos municípios consagrados como polos de crescimento, com a criação de oportunidades de emprego e em consequência a motivação para a migração de pessoas para esses lugares auspiciosos.

A questão da mobilidade urbana no Brasil vinculada a um excedente de veículos e crescimento econômico, também inclui o processo de aglomeração urbana, que pode ter sido iniciado a partir da segunda metade do século XX com a industrialização brasileira, condicionando a migração campo/cidade (SINGER, 2002, p. 29-155). Essa implantação da indústria foi idealizada em um momento de necessidade de substituição das importações, logo após a crise de 1929 (TAVARES, 1972, p. 27-143) e consolidada nas décadas de 1960 , 1970 e 1980, deixando um significativo registro de emigração nordestina, em virtude de uma industrialização, que nesse período não deve ser considerada como brasileira em escala nacional, pois seu esforço foi centrado no Sudeste (SINGER, 1976, p. 12-115 e 1980, p.29-57).

Uma melhor explicação sobre aglomeração urbana no Brasil poder ser encontrada na publicação do IBGE, originada do Censo Demográfico (2010, p. 5-23), intitulada "Aglomerados Subnormais Informações Territoriais", esse termo aglomerados subnormais, foi a denominação dada pelo IBGE, para favela, comunidade, grotão, vila, mocambo, entre outros setores de mesma semelhança. Esse trabalho que utilizou Levantamento de Informações Territoriais obteve como resultado, conhecimentos de características espaciais, padrões urbanísticos e condições de acessibilidade existentes nesses aglomerados, que poderão auxiliar no planejamento de políticas públicas de mobilidade urbana.

Os dados coletados nesse levantamento mostram a dimensão do problema da aglomeração espacial brasileira. Exemplificando, essa pesquisa mostra que cerca de 317.000 setores censitários ${ }^{3}$ em que o país foi dividido para coletar dados pelo IBGE, 15.868 foram identificados como setores subnormais (cerca de 5\%) e esses setores formam os 6.329 aglomerados subnormais identificados no país (IBGE, 2010, p.5-23).

Numa breve síntese dos aspectos abordados, para fortalecer a capacidade de análise sobre mobilidade urbana, verifica-se influência dos fatores históricos da formação econômica brasileira durante sua industrialização, época em que esse evento mobilizou grandes contingentes de nordestinos para o Sudeste, criando necessidades de habitação e locomoção para o trabalho entre outras. Através dessa organização industrial é possível explicar como se formaram os aglomerados subnormais, do sudeste brasileiro na segunda metade do século XX.

Os aglomerados subnormais representam as consequências de um processo migratório de grandes proporções, que pressupõem a inexistência de um planejamento urbano compatível com essas vicissitudes, decorrentes de contingências

\footnotetext{
3 Setor Censitário é unidade territorial de coleta das operações censitárias, definido pelo IBGE, com limites físicos identificados, em áreas contínuas e respeitando a divisão político-administrativa do Brasil. AGREGADOS POR SETORES CENSITÁRIOS DOS RESULTADOS DE UNIVERSO. 2 ed. Disponível em: www.ibge.gov.br/ho-me/estatistica/popu-lacao/de-faulttab_agregado.shtm.
} 
econômicas externas. Na contramão da crise bancária que teve início em 2007 e tornou-se uma crise global em 2008, observa-se que o Brasil implementou uma série de medidas de promoção do crescimento, como mencionado em parágrafos anteriores, visando rechaçar os impactos provenientes desse desequilíbrio. Essa crise econômica foi considerada a mais severa enfrentada pelas economias capitalistas desde 1929, é também uma crise social, pois o número de desempregados passou de cerca de 20 milhões para 50 milhões ao fim de 2009 de acordo com a Organização Internacional do Trabalho, (BRESSER-PEREIRA, 2010, p.2-24).

Essas considerações econômicas procuram estabelecer uma relação com os fatos mais recentes, que provocaram desequilíbrio no espaço urbano dos municípios brasileiros mais destacados economicamente, quando a questão da mobilidade urbana passou a fazer parte das discussões nas esferas governamentais. Assinala-se aqui a criação do Ministério das Cidades em 2003, com suas atribuições de elaborar políticas públicas de desenvolvimento urbano, de habitação, de transporte urbano e de trânsito (MINISTÉRIO DAS CIDADES, 2005, p.6-48).

Os deslocamentos são realizados através de veículos, vias e toda infraestrutura necessária, que possibilitam o ir e vir cotidiano. As cidades que enfrentam o fenômeno da aglomeração urbana lidam com a limitação dessa estrutura para o fluxo de pessoas e transportes, principalmente quando esse fenômeno populacional ocorre de modo inopinado, como no caso brasileiro, nesse citado crescimento econômico.

De acordo com Merlin (1991, p.306-307), os transportes e a acessibilidade têm uma influência significativa não só sobre a localização das atividades, mas também sobre a escolha dos locais de referência das famílias. No contexto da mobilidade urbana estão presentes os aspectos organizacionais dos usos e ocupação da cidade e as alternativas que garantam o acesso das pessoas aos bens e serviços, assim estão relacionados os locais de trabalho, escolas, hospitais, praças, áreas de lazer e os centros de comércio e serviços.

O conceito de acessibilidade refere-se de modo geral à condição de acesso, vinculada aos diversos tipos e situações, dentro de um âmbito da mobilidade urbana. A acessibilidade possui grande utilidade no planejamento urbano, identificando áreas específicas na estrutura básica da mobilidade humana e se encontra intimamente relacionada à qualidade de vida das pessoas (VASCONCELLOS, 2000, p.1-7; GOTO, 2000). Ingram (1971) define acessibilidade de um local como um atributo vantajoso para ultrapassar alguma forma de resistência ao deslocamento (CARDOSO, 2006).

É possível entender que uma gestão de políticas públicas de desenvolvimento urbano, não deve prescindir de uma organização espacial, que priorize a facilidade de acesso que uma população deve ter, considerando sua diversidade, as necessidades especiais dos usuários, a nova tendência de expectativa de vida, com faixa etária mais elevada e com as limitações físicas correspondentes e a nova dinâmica migratória condicionada pelos novos padrões de produção deste século XXI.

\section{MIGRAÇÃO E MOBILIDADE URBANA}

Os municípios mais dinâmicos, em termos de crescimento econômico, neste século provocam diversos tipos de deslocamentos de pessoas, num sentido centrípeto, principalmente em busca de emprego e renda, condicionando redes e trajetórias migratórias, que consequentemente produzem uma aglomeração urbana, sobre espaços que não foram planejados para grandes surtos populacionais. 
A discussão sobre a dinâmica dos municípios polos de crescimento tornou-se importante a partir da década de 1970, quando foi evidenciado no Brasil um processo caracterizado por uma desconcentração industrial dos grandes centros industriais, principalmente no Sudeste. Esse assunto estabelece uma conexão com o processo migratório de pessoas. Inicialmente é interessante posicionar parte da discussão sobre desindustrialização, que aparece como incentivada pelo governo federal na perspectiva de desenvolvimento regional, autorizando governos estaduais e municipais a promoverem incentivos fiscais para a implantação de indústrias em seus territórios. Uma outra forma de analisar é admitir a mudança no sistema capitalista de produção, com o emprego de novas tecnologias e a estratégia da terceirização. Observa-se também que a desconcentração industrial inicia-se nos países desenvolvidos, como Estados Unidos e França buscando melhores alternativas de produção nas suas áreas industriais.

O Brasil aparece na década de 1970 com essa motivação associada a diversas causas, principalmente o aproveitamento dos investimentos do governo em infraestrutura de transporte e energia elétrica nas regiões periféricas como afirma Diniz (1991). Desse processo de desconcentração, outros lugares foram beneficiados com investimentos possibilitando novos direcionamentos dos fluxos migratórios e consequentemente o surgimento de necessidades locais em função da expansão do nível de emprego. Para Soares (2006) essa desconcentração seria potencializada pela especulação imobiliária e por fatores ligados ao próprio mercado de trabalho.

$\mathrm{O}$ processo de desconcentração espacial da indústria deu origem a um tipo de migração, caracterizada pela saída de migrantes, principalmente das regiões metropolitanas de São Paulo e Rio de Janeiro (DINIZ, 1993; DINIZ; CROCCO 1996). Esse processo beneficiou as regiões Centro-Oeste; Nordeste e Norte, através do desenvolvimento de determinados setores industriais (NEGRI 1994; PACHECO, 1999; SABOIA 2000). Nessa perspectiva outros centros dinâmicos regionais passaram a atrair os fluxos migratórios, que anteriormente tinham destinos tradicionais, marcados pelo processo de industrialização do Brasil.

As novas formas de produzir exigiram tipos diferentes de migração, caracterizado por deslocamentos de curta distância entre municípios, estabelecendo um movimento pendular e a migração de retorno especificando a volta de migrantes, para suas origens ou para outros polos constituídos com a estratégia de desconcentração. $\mathrm{O}$ conceito de "migração pendular" é antigo na Geografia e aparece nas análises de Beaujeu-Garnier (1980), dentre outros clássicos da Geografia Humana. Esse tipo de deslocamento não é considerado como uma migração por alguns autores, ele consiste na movimentação de trabalhadores, que normalmente deixam seu município de domicílio no período da manhã para cumprir jornada de trabalho no município de maior dinamismo, retornando somente à noite para seu domicílio.

A desconcentração como mostra no Quadro 3 a seguir, com a modificação na participação do Produto Interno Bruto - PIB das grandes regiões destacam o Nordeste, Norte e Centro-Oeste com significativa ampliação no período de 1970 a 1985.

Quadro 3. Participação das Grandes Regiões no PIB 1970 a 1985.

\begin{tabular}{|c|c|c|c|c|}
\hline Regiões & $\mathbf{1 9 7 0}$ & $\mathbf{1 9 7 5}$ & $\mathbf{1 9 8 0}$ & $\mathbf{1 9 8 5}$ \\
\hline Centro-Oeste & 3,9 & 4,1 & 5,4 & 6,0 \\
\hline Sul & 16,7 & 17,9 & 17,0 & 17,1 \\
\hline Sudeste & 65,5 & 64,9 & 62,3 & 59,1 \\
\hline Nordeste & 11,7 & 11,1 & 12,0 & 13,6 \\
\hline Norte & 2,2 & 2,0 & 3,3 & 4,1 \\
\hline
\end{tabular}

Fonte: IBGE, 1992/CAIADO, 2002.Elaboração dos autores. 
Nesse período delimitado no quadro acima reforçam-se as bases da industrialização no Nordeste, destacando-se a riqueza das matérias-primas como, a cana-de-açúcar o petróleo e o gás natural. Os principais polos industriais foram localizados nas regiões metropolitanas, sendo as indústrias alimentícias e têxteis as mais tradicionais, seguidas das metalúrgicas, químicas e de produtos eletroeletrônicos (GASPAR, 2003). O Norte destacou-se com seu polo Industrial de Manaus com aproximadamente 600 indústrias de alta tecnologia (SERÁFICO, 2005).

A região Centro-Oeste teve grande destaque em termos de investimentos em transportes e comunicação considerando que esse período contempla a construção de Brasília (GOMES; NETO, 2000). Os investimentos destinados à construção de estradas como a Belém-Brasília fortaleceu polos de crescimento econômico como o de Goiânia, considerada a cidade que detém o quarto maior polo de confecções do Brasil e o polo de Imperatriz no Maranhão, que se destaca pela força do comércio atacadista e varejista, na região sul-maranhense, servindo também ao sul do Pará e norte do Tocantins.

\section{AGLOMERAÇÃO URBANA CONDICIONADA PELA MIGRAÇÃO}

O debate sobre distribuição populacional no Brasil passou a despertar um outro tipo de interesse, quando no ano de 2000 o Instituto Brasileiro de Geografia e Estatística (IBGE) informou que 80\% da população brasileira mora em cidades, nesse caso entendendo cidade como o espaço urbano do município. De acordo com Ervatti (2011) o Brasil registrou intensos deslocamentos no período marcado pelas décadas de 1960-1980, quando grandes volumes de migrantes se deslocaram do campo para a cidade, delineando um processo de intensificação da urbanização e caracterizando áreas de expulsão ou emigração, tendo como exemplo, a região Nordeste e os estados de Minas Gerais, Espírito Santo, Santa Catarina e Rio Grande do Sul; e áreas de atração ou forte imigração populacional, formadas pelos estados de São Paulo e do Rio de Janeiro, nos seus núcleos de industrialização.

As aglomerações urbanas explicadas por Singer (2002), em seu esforço de descobrir a função econômica da cidade, são justificadas em virtude da possibilidade de estabelecer um bom nível de cooperação entre as pessoas, no desempenho de atividades próximas umas das outras, como também na indústria de transformação e no comércio onde a divisão social do trabalho fragmenta a atividade em milhares de núcleos especializados, cuja produção necessita ser transportada, concentrada, financiada e redistribuída. A aglomeração urbana compreende, por definição, a zona fortemente povoada, normalmente afastada do centro da cidade, mas contínua aos limites da cidade (BEAUJEU-GARNIER, 1997).

Essa composição econômica de mão de obra e atividade produtiva ocorre em função do sistema capitalista, na busca da acumulação de capital de forma concentrada no espaço, que atrai grandes fluxos migratórios como afirma Singer (2002). Esse autor também afirma que os planos de desenvolvimento regional criam incentivos para direcionar fluxos de capital para áreas mais atrasadas e diante disso criam-se novos centros de concentração espacial do capital, priorizando menores custos com baixo preço de mão de obra, incentivos fiscais e menor rigidez nas normas ambientais.

A migração de retorno já mencionada, segundo Cunha e Baeninger (2005), apresenta registros de 1,1 milhão de pessoas na década de 70, e quase 3,8 milhões, na década de 1990. Esses volumes podem indicar uma possibilidade de saída de pessoas das grandes metrópoles em busca dos novos centros 
de crescimento, que já apresentam problemas de aglomeração urbana, considerando que no retorno, provavelmente o migrante, mesmo sendo oriundo da zona rural apresente preferência pela cidade, onde estão concentrados os maiores setores de meios de produção do município. Nessa discussão a migração figura como ponto de partida para a aglomeração, que se origina do retorno do migrante radicado numa metrópole.

\section{Aglomeração urbana em Imperatriz - MA}

Imperatriz é o município mais importante do estado depois da capital. Está situado na parte sul do Maranhão e sua ocupação espacial ou povoamento originou-se através dos fluxos migratórios, condicionados pelos ciclos de desenvolvimento econômico, que constituíram a base do grande crescimento econômico desse município. Os ciclos do arroz, madeira, ciclo do ouro e principalmente da construção da rodovia Belém-Brasília são considerados neste estudo, como os propulsores do crescimento populacional da microrregião de Imperatriz, demonstrado através do Quadro 4 a seguir.

Quadro 4. Evolução populacional de Imperatriz 1940 a 2010.

\begin{tabular}{|c|c|c|c|}
\hline ANOS & TOTAL & URBANA & RURAL \\
\hline 1940 & 9.331 & 1.002 & 8.329 \\
\hline 1950 & 14.064 & 1.399 & 12.665 \\
\hline 1960 & 39.169 & 4.144 & 35.025 \\
\hline 1970 & 80.827 & 46.117 & 34.710 \\
\hline 1980 & 220.095 & 111.705 & 108.390 \\
\hline 1991 & 276.502 & 210.051 & 66.451 \\
\hline 2000 & 230.566 & 218.673 & 11.893 \\
\hline 2010 & 247.553 & 234.671 & 12.882 \\
\hline
\end{tabular}

Fonte: Censos Demográficos: 1940; 1950; 1960; 1970; 1980; 1991; 2000 e 2010. Elaboração dos autores.

Os números que formam a população nesse quadro, a partir de 1960 são expressivos, principalmente quando são analisados os registros históricos de Imperatriz em termos de comunicação através de estradas, no entanto Considerando a dificuldade de acesso a esse município, não somente pela quase inexistência de estradas como também a precariedade de meios de transporte, presume-se que, grande parte dessa população foi originada pelo crescimento vegetativo ${ }^{4}$. A taxa de fecundidade da região Nordeste, registrada pelo IBGE, no Censo Demográfico (CD) de 1970 foi 5,8 e no Censo de 1980 4,4. Esses dados favorecem o entendimento de que, grande parte dessa população, mormente aquela registrada até o Censo de 1980, não foi oriunda de processo migratório.

Nesse aspecto da fecundidade o censo mostra que, das 54.380 mulheres com idades de 15 anos ou mais, 37.945 tiveram filhos totalizando 202.432 nascidos, sendo 150.813 filhos vivos (CD, 1980, v1t4n7, p.335). O que se pretende com essas análises é tentar reconstruir o início da aglomeração, que se formou em um breve espaço de tempo, no município de Imperatriz. A aglomeração urbana desse município começou a ser definida a partir de 1981 com o desmembramento do município de AçailândiaMA, perdendo grande parte da área rural e na década de 1990 outros municípios, que conquistaram suas emancipações contribuíram para que o setor rural chegasse a ficar quase inexistente em Imperatriz (IBGE CIDADES, 2015).

A infraestrutura e superestrutura conforme Marx (2006) nasceram da influência da classe dominante, com poderes políticos e econômicos, viabilizando o transporte de migrantes e os meios de produção para o trabalho no meio rural. A utilização dessa mão de obra migrante na lavoura local e nos

${ }^{4} \mathrm{O}$ crescimento vegetativo refere-se ao crescimento da população em um determinado território com base no número de pessoas que nasceram em um determinado período em comparação com o número de falecimentos. É a diferença entre os nascimentos e mortes, ou seja, entre a taxa de natalidade e a taxa de mortalidade, geralmente ele é expresso em permilagem (IBGE - Biblioteca, 2016). 
castanhais de Marabá-PA foi semelhante ao regime de servidão por dívida (MOREIRA, 1997). O início da atividade concentrou-se no campo e com o declínio deste surge o comércio, estruturando-se com apoio da recém-inaugurada rodovia Belém-Brasília e a implantação da superestrutura institucional apoiada pelo projeto geoestratégico Calha Norte do governo federal, que contemplava a instalação de diversas instituições públicas em Imperatriz (NASCIMENTO, 2005).

\section{CONSIDERAÇÕES FINAIS}

As abordagens iniciais deste artigo priorizaram caminhos que justificassem a formação de aglomerados urbanos no Brasil, originados através de medidas impulsionadoras de crescimento econômico, que condicionaram fluxos migratórios para centros urbanos dinâmicos. Considerando que a pretensão deste estudo foi conduzir discussões em torno da mobilidade urbana envolvida por esses fluxos, é importante ressaltar que o aspecto da migração referiu-se aos deslocamentos do meio rural para o urbano, sem mencionar, por exemplo, os movimentos migratórios do Nordeste para atividades agrícolas no Sudeste.

Os exemplos de crescimento econômico apresentados tiveram suas origens fincadas em fatores exógenos, como a crise de 1929, que obrigou o país a pensar num modelo de substituições das importações e consequentemente encaminhar o processo de industrialização, que se concretizou no Sudeste. Esse processo foi apresentado como um propulsor de fluxos migratórios e de formação de aglomerados urbanos nessa região.

Mostrou-se com dados evolutivos do quadro 1, que o Brasil ingressou num processo de urbanização conduzido pelos planos nacionais de desenvolvimento, que através de investimentos em infraestrutura como energia elétrica, estradas, telecomunicações, transportes e modernização da agricultura criou novos polos regionais de crescimento econômico, com diversas oportunidades de empregos no meio urbano.

Além dos planos de desenvolvimento, que promoveram mudanças nos destinos dos fluxos migratórios com a desconcentração industrial do Sudeste foi evidenciada a crise financeira global de 2008 e a reação da economia brasileira, criando alternativas de geração de empregos, incentivando o consumo interno e aumentando a concentração espacial urbana.

A metamorfose sofrida na distribuição espacial da população brasileira pode ser considerada como um fenômeno que superou as expectativas, para um país com as características territoriais como o Brasil, com imensas riquezas naturais, que poderiam estabelecer certo equilíbrio na sua distribuição populacional (rural/urbano), contudo o emprego de políticas neoliberais que integram plenamente os países através da maior abertura dos mercados internos reduzem o poder econômico nacional em função da hegemonia global.

Projetar uma mobilidade urbana de forma adequada em determinados polos de crescimento, diante da dependência econômica global exige mais que um esforço complexo. Essa possibilidade, nesses casos, algo quase impossível, organizar um espaço extremamente desorganizado, constituído por diversos "aglomerados subnormais" e áreas de expansão, contíguas a um espaço urbano ilimitado, disputado pelas incorporadoras imobiliárias. A experiência de Imperatriz utilizada nesse trabalho exemplifica a formação de um aglomerado urbano constituído por surtos de crescimento econômico, que utilizou-se das migrações, como um processo de povoamento, formador das bases econômicas desse município. 


\section{REFERÊNCIAS}

BAENINGER, Rosana. Cenários da migração no Brasil nos anos 90. Caderno do CRH, Salvador, v. 18 n. 43, 2005.

BALBIM, Renato. Transporte Integrado Social: Uma proposta para o pacto da mobilidade urbana. Nota Técnica Dirur $n^{\circ}$ 04/2013). Brasília: IPEA, 2013.

BARROS, Edelvira Marques Moreira. Imperatriz, memória e registro. Imperatriz: Ética, 1996.

BEAUJEU-GARNIER, Jaqueline. Geografia da população. São Paulo: Companhia Editora Nacional, 1980.

BRASIL. Ministério das cidades. Lei 12.587 de 03 de janeiro 2001. Política Nacional de Mobilização Urbana. Disponível em: <http://www.cidades.gov.br.> Acesso em: 06 mar. 2020.

\section{LEI $\mathrm{n}^{\circ}$ 12.587/2012: Lei da Política} Nacional de Mobilidade Urbana; Lei de Mobilidade Urbana. Brasília, 2012. Disponível em: www.planalto.gov.br/ccivil_03/_ato20112014/2012/lei/112587.htm. Acesso em 10 mar. 2020.

Ministério das Cidades. Mobilidade e política urbana: subsídios para uma gestão integrada /Coordenação de Lia Bergman e Nidia Inês Albesa de Rabi. Rio de Janeiro: IBAM, 2005, p. 6-48. Disponível em: http://www.ibam.org.br/media/arquivos/estudos/mobi lidade.pdf. Acesso em: 03 mar. 2020.

BRESSER-PEREIRA, Luiz Carlos. A crise financeira global e depois: um novo capitalismo? Novos estud. - CEBRAP n.86 São Paulo Mar. 2010, p. 2-24. Disponível em: http://dx.doi.org/10.1590/S0101-

33002010000100003. Acesso em: 05 mar. 2020.

CAIADO, Aurilio Sergio Costa. Desconcentração industrial regional no Brasil (1985-1998). Instituto de Economia Tese (doutorado). Campinas, SP: UNICAMP, 2002. Disponível em: www.bibliotecadigital.unicamp.br/document/?code= vtls000289890. Acesso em: 24 fev. 2020.

CARDOSO. Carlos Paiva. Acessibilidade, alguns conceitos e indicadores. Revista dos Transportes Públicos, v. 112, p. 77-86. São Paulo. ANTP, 2006. Disponível em: www.sinaldetransito.com.br/artigos/acessibilidade_si stema viario.pdf. Acesso em: 05 mar. 2020.
CIRETRAN. Circunscrição Regional de Trânsito de Imperatriz. Registros de veículos novos em Imperatriz. In: Franklin, Adalberto. A história econômica de Imperatriz. Imperatriz: Ética, 2008.

CRISTO, Fábio de. O hábito de usar automóvel tem relação com o transporte coletivo ruim? 2013. 158 f. Tese (Programa de Pós-Graduação em Psicologia Social, do Trabalho e das Organizações). Universidade de Brasília Brasília: UNB, 2013.

CUNHA, José Marcos Pinto. Migração e urbanização no Brasil: alguns desafios metodológicos para análise. São Paulo em perspectiva. v. 19, n4 p 3-20; out/dez 2005.

DINIZ, C. C. Dinâmica regional da indústria no Brasil: início da desconstrução, risco de reconstrução. Belo Horizonte, Tese de Prof. Titular, UFMG, 1991.

DINIZ, C. C. Desenvolvimento poligonal no Brasil: Nem desconcentração, nem contínua polarização. Nova Economia, v. 3, n. 1, set. 1993. In: SABOIA, João Luiz Maurity. A continuidade do processo de desconcentração regional da indústria brasileira nos anos 2000. Disponível em: www.scielo.br/scielo.php?script $=$ sci nlinks $\&$ ref $=000$ 111\&pid. Acesso em: 23 fev. 2020.

DINIZ, C. C.; CROCCO, M. A. Reestruturação econômica e impacto regional: $\mathrm{O}$ novo mapa da indústria brasileira. Nova Economia, v. 6, n. 1, jul. 1996. In: SABOIA, João Luiz Maurity. A continuidade do processo de desconcentração regional da indústria brasileira nos anos 2000. Disponível em: www.scielo.br/scielo.php?script...416120070002000 0700015. Acesso em: 15 fev. 2020.

ERVATTI, Leila Regina. O panorama dos deslocamentos populacionais no Brasil: PNADs e Censos Demográficos. Gili, Barcelona, España. Rio de Janeiro: IBGE, 2011.

FERREIRA, Aurélio Buarque de Holanda. Dicionário da língua portuguesa, 2013.

GASPAR, Lúcia. O Nordeste do Brasil. Fundação Joaquim Nabuco, Recife: 2003. Disponível em: <http://basilio.fundaj.gov.br/pesquisaescolar/>. Acesso em: 06 mar. 2020.

GATERSLEBEN, Birgitta. (2007). The psychology of sustainable transport. Traffic to the Quality of Urban Life: Problems, Causes and Solutions, ISBN: 978-0-08-044853-4 e ISBN: 978-0-08-048144-9, Edited by: Tommy Gärling, Linda Steg. Published: 2007, p. 676-679. 
GIRARDI, Eduardo Paulon. Atlas da questão agrária brasileira: alguns temas sobre o rural brasileiro. Boletim Regional, v. 9, p. 41-65, 2010. Disponível em:

http://www2.fct.unesp.br/nera/atlas/estrutura_fundiari a.htm. Acesso em: 05 mar. 2020.

GOMES, Gustavo Maia; NETO, Aristides Monteiro. Quatro Décadas de Crescimento Econômico no Centro-Oeste Brasileiro: Recursos Públicos em Ação. Brasília: IPEA/ Texto para discussão Nr. 712, 2000.

GOTO, Massa. (2000). Uma análise de acessibilidade sob a ótica da equidade: o caso da região metropolitana de Belém. São Carlos. Dissertação (Mestrado) Escola de Engenharia de São Carlos. Universidade de São Paulo.

IBGE Censo Demográfico. Fecundidade. 1970, p. 112-124, v1, t5 e 1980, p. 242-271. Vol 1 Tomo 4 n 7.

IBGE Censo 2010 Aglomerados Subnormais: Informações Territoriais, resultados gerais do Brasil. Rio de Janeiro: DGC/CGEO, DGC/CETE, DPE/COPIS, COC/CNEFE, 2010, p. 5-23. Disponível em: http://www.ibge.gov.br/home/presidencia/noticias/im prensa/ppts/00000015164811202013480105748802. pdf. Acesso em: 05 mar. 2020.

IBGE, Cidades. Histórico de municípios maranhenses. Rio de Janeiro: IBGE, 2015. Disponível em www.cidades.ibge.gov.br/. Acesso em: 17 fev. 2020.

INCT/Observatório das Metrópoles. Evolução da frota de automóveis e motos no Brasil 20012012(Relatório

2013

www.observatoriodasmetropoles.net. Acesso em 04/07/2016.

INGRAM, D. R. (1971) The Concept of Accessibility: A Search for an Operational Form. Regional Studies, v. 5, n. 2, p. 101-107. Disponível em: citeseerx.ist.psu.edu/viewdoc/download?doi. Acesso em: 17 fev. 2020.

IPEA. Indicadores de mobilidade urbana da PNAD 2012. Comunicados do IPEA n ${ }^{\circ} 161$. Brasília, 2013. Disponível em: www.ipea.gov.br/portal/index.php?optioncom_conte nt\&view=article\&id. Acesso em 13 fev. 2020.

IPEA. Série Eixos do Desenvolvimento Brasileiro. A mobilidade Urbana no Brasil ( $\mathrm{O}$ estudo foi elaborado por Carlos Henrique Ribeiro Carvalho, Eduardo Alcântara Vasconcellos, Ernesto Galindo,
Rafael Henrique Moraes Pereira e Vicente Correia de Lima Neto e integra o livro Infraestrutura Social e Urbana no Brasil: subsídios para uma agenda de pesquisa e formulação de políticas públicas, editado por Maria da Piedade Morais e Marco Aurélio Costa. Comunicados do IPEA $\mathrm{n}^{\mathbf{0}}$ 094. Brasília, 2011. Disponível em: www.ipea.gov.br/portal/index.php?option=com_cont ent\&view=article\&id. Acesso em 18 fev. 2020.

IPEA. Tarifação e financiamento do transporte público urbano. Nota Técnica 02. Brasília: IPEA, 2013. Disponível em: www2.camara.leg.br/acamara/altosestudos/...no.../nota-tecnica-2-2013-ipea. Acesso em: 14 fev. 2020.

JAKOBSSON, C. (2007). Instrumental motives for private car use. In: T. Gärling, \& L. Steg (Eds.), Threats from car traffic to the quality of urban life -problems, causes, and solutions(1st ed., pp. 205217). Bingley, UK: Elsevier Science. Disponível em http://www.gu.se/english/research/publication?public ationId=162138. Acesso em: 20 fev. 2020.

MARX, Karl. Contribuição à crítica da economia política. São Paulo: Martins Fontes, 2006.

MERLIN, P. Géographie, économie et planification des transports. Paris, PUF, 1991, p.306-307. Disponível em: www.persee.fr/doc/geo 000340101993 num 102 571_21152_t1_0306_0000_2. Acesso em $17 \mathrm{fev}$. 2020.

MOREIRA, Zequinha. Simplício Moreira: precursor do desenvolvimento de Imperatriz. Imperatriz: Ética, 1997.

MORRIS, J.M.; Dumble, P.L.; Wigan, M.R. 1979. Accessibility indicators for transport planning. Transportation Research, Part A, v.13, n.2, p.91109.

NASCIMENTO, Durbens Martins. Projeto Calha Norte: Política de defesa nacional e segurança hemisférica na governança contemporânea. Tese (doutorado). Belém, NAEA/UFPA, 2005. Disponível em: https://cpdoc.fgv.br/sites/default/files/militaresamazonia/txt_DurbensNascimento.pdf. Acesso em: 23 fev. 2020.

NEGRI, B. Concentração e desconcentração industrial em São Paulo (1880-1990). 1994. 280 f. Tese (Doutorado em Economia) - Universidade Estadual de Campinas, Campinas, [Links] 1994. In: SABOIA, João Luiz Maurity. A continuidade do processo de desconcentração regional da indústria brasileira nos anos 2000. Disponível em: 
www.scielo.br/scielo.php?script $=$ sci nlinks \&ref $=000$ 238\&pid. Acesso em: 01 mar. 2020.

PACHECO, C. A. Novos padrões de localização industrial? Tendências recentes dos indicadores da produção e do investimento industrial. Texto para Discussão, n. 633. IPEA, Brasília, mar. 1999. In: SABOIA, João Luiz Maurity. A continuidade do processo de desconcentração regional da indústria brasileira nos anos 2000. Disponível em: wWw.scielo.br/scielo.php?script $=$ sci nlinks\&ref $=000$ 238\&pid. Acesso em: 01 mar. 2020.

PRATES, D. M.; FARHI, M. A crise financeira internacional, o grau de investimento e a taxa de câmbio do real. Campinas: IE/UNICAMP, 2009. (Texto para Discussão, n. 164).

PRATES, D. M.; CUNHA, M. A.; LÉLIS, C. T. M. $\mathrm{O}$ Brasil e a crise financeira global: avaliando os canais de transmissão nas contas externas. Rev. Econ. Contemp., Rio de Janeiro, v. 15, n. 1, p. 6291, jan./abr. 2011.

RODRIGUES Juciano Martin. Crise de mobilidade urbana: Brasil atinge marca de 50 milhões de automóveis. Instituto Nacional de Ciência e Tecnologia, Observatório das Metrópolis, 2013. Disponível em: www.observatoriodasmetropoles.net/index.php.

Acesso em: 12 fev. 2020.

SABOIA, João Luiz Maurity. A continuidade do processo de desconcentração regional da indústria brasileira nos anos 2000. Disponível em: www.scielo.br/scielo.php?script=sci_arttext...635120 13000200001. Acesso em: 27 fev. 2020.

SINGER, Paul. Economia política da urbanização. São Paulo: Contexto, 2002.

$\mathrm{O}$ combate à crise pelo Governo Federal. Teoria e Debate, n. 81, mar./abr. 2009, v. 22, n. 83, p. 43-45, jul./ago.

Implicações Econômicas e sociais da dinâmica da população brasileira 1976. Disponível em: www.cebrap.org.br/v2/files/../implicacoes_economic as_e_sociaispdf. Acesso: 11 mar. 2020.

Migrações internas: considerações teóricas sobre o seu estudo. In: MOURA, Hélio (coord.), Migração Interna. Textos Selecionados, tomo I, Fortaleza: Banco do Nordeste, 1980.

SERÁFICO, José Seráfico; Marcelo. A Zona Franca de Manaus e o capitalismo no Brasil. Estudos Avançados, Print version, ISSN 0103-4014On-line version ISSN 1806-9592Estud. av. vol.19 no.54 São Paulo May/Aug. 2005. Disponível em: http://dx.doi.org/10.1590/S0103-

40142005000200006. Acesso em: 23 fev. 2020.

SOARES, M. R. M. Migração intrametropolitana e movimentos pendulares na Região Metropolitana de Belo Horizonte: o caso do município de Contagem -1991/2000. 1-141 p. Tese (Doutorado) UFMG, 2006.

STEG, L. (2005). Car use: Lust and must. Instrumental, symbolic and affective motives for car use. Transportation Research Part A ,39, 2-12.

TCU. Ações do Governo para reduzir os efeitos da crise. Versão simplificada das Contasdo Governo da República, 2009, p. 1 e 2. Disponível em: <http://portal2.tcu.gov.br/portal/page/portal/TCU/co munidades/contas/contas_governo/contas_09/Textos/ Ficha $\% 201 \% 20-\% 20$ Analise $\% 20$ da $\% 20$ Crise.pdf $>$.

Acesso em: 10 mar. 2020.

TAVARES, Maria da Conceição. Da substituição de importações ao capitalismo financeiro. Rio de Janeiro, Zahar, 1972, p. 27-143.

VASCONCELLOS, Eduardo Alcântara. Transporte urbano nos países em desenvolvimento: Reflexões e propostas. São Paulo: Annblume, 2000, p. 1-7. In: CARDOSO, Carlos Eduardo de Paiva. Acessibilidade alguns conceitos e indicadores. Revista dos Transportes Públicos, v. 112, p. 77-86. São Paulo. ANTP, 2006. Disponível em: www.sinaldetransito.com.br/artigos/acessibilidade_si stema viario.pdf. Acesso em: 05 mar. 2020. 